\title{
Noninvasive Assessment of Arterial Stiffness and Risk of Atherosclerotic Events in Children
}

\author{
YACINE AGGOUN, ISABELLE SZEZEPANSKI, AND DAMIEN BONNET \\ Pediatric Cardiology, Hôpital Necker-Enfants Malades, 75015 Paris, France
}

\begin{abstract}
ABST
Noninvasive assessment of vascular dysfunction in the pedi-
atric population has taken advantage of the development of
high-resolution ultrasound techniques. The most frequently used
methods are the quantification of flow-mediated endothelium-
dependent dilation of the brachial artery and measurement of the
intima-media thickening of the carotid artery. Both reduced
flow-mediated dilation and increased intima-media thickness
have been proven to correlate with late cardiovascular events
and/or mortality in adults. As these noninvasive methods can
easily be applied in children, there have been recent investiga-
tions in high-risk pediatric patients harboring classical cardio-
vascular risk factors. Endothelial dysfunction and increased
thickness of the intima media are currently observed in children
\end{abstract}
ABSTRACT

Atherosclerosis begins in childhood as deposits of cholesterol and its esters, referred to as fatty streaks, in the intima of large muscular arteries. Evidence regarding the associations of adult coronary artery disease risk factors with atherosclerosis in young persons have been described (1). These observations raise implications for the long-range prevention of coronary artery disease, starting in the pediatric practice. Before the use of high-resolution ultrasound techniques to assess vascular function, anatomical and functional evidence for atherogenesis could only be recognized by invasive investigations or on postmortem examination (2). Today, these noninvasive methods are commonly used to assess endothelial function and to detect early anatomical evidence of atherogenesis in adult and pediatric populations. The most widely used test to evaluate endothelial function measures the vasodilator response to increased blood flow of the brachial artery (flow mediated vasodilatation) (3). Adult studies have demonstrated that the endothelial function of the peripheral circulation is closely related to

Received December 15, 2004; accepted March 30, 2005.

Correspondence: Damien Bonnet, M.D., Ph.D., Service de Cardiologie Pédiatrique, Hôpital Necker-Enfants Malades, 149, rue de Sèvres 75015 Paris, France; e-mail: damien.bonnet@nck.ap-hop-paris.fr

DOI: 10.1203/01.PDR.0000170900.35571.CB with familial hypercholesterolemia, obesity, and type 1 diabetes mellitus. The association of early vascular dysfunction with a known risk factor is an important issue as these anomalies precede the formation of atherosclerotic plaques. Therefore, they may help in stratification of the risk for cardiovascular event and to better tailor therapeutic interventions in at risk children. Finally, these methods have been applied in specific pediatric populations, such as children with end-stage renal disease, chronic parenteral nutrition, HIV infection, and coarctation of the aorta. In these conditions, endothelial dysfunction and vascular remodeling are also present early in life and these data raise new possibilities in the understanding of the pathogenesis of atherosclerosis in these populations. (Pediatr Res 58: 173-178, 2005) that of the coronary circulation. The remodeling of the large arteries can be evaluated by the measure of the thickening of the intima and media of the common carotid arteries, or of the aorta (4). These approaches give an estimation of the local or regional function of the examined arterial bed. However, a more global evaluation of the physical properties of the arterial system can be given by the measure of the pulse wave velocity that derived from the complex interactions between the ventricular performance, the physical properties of the arterial system, and rheological characteristics of the blood (5). Additionally, analysis of the pulse wave form by tonometry of applanation provides a noninvasive means to record local arterial pressure and wave reflection (6).

This past decade, endothelial dysfunction has been demonstrated noninvasively in children harboring various coronary artery disease risk factors. Accordingly, increased thickening of the intimal and medial layers has been observed in these conditions. Ultrasound evaluation of vascular function has opened new perspectives into pediatric vascular disease and could provide a valuable supplement in the evaluation of high risk pediatric patients within a clinical setting.

Here, we will give a brief summary of the noninvasive methods to evaluate vascular function in children and review the recent 
data available to show the potential of these techniques for assessing atherogenic risk in the pediatric population.

\section{NONINVASIVE METHODS FOR THE EVALUATION OF VASCULAR FUNCTION}

Consistent testing conditions are needed to obtain accurate results. The International Brachial Artery Reactivity Task Force lists criteria that should be fulfilled for participation in multicenter trials (7). These criteria could be applied to clinical testing centers. In the pediatric practice, many puzzling factors can be difficult to control, such as fasting, menstrual cycle in adolescents, drug intake, and body mass differences in large cohorts of patients. In spite of these limitations, the results obtained in similar pediatric populations by different groups are consistent. This suggests that ultrasound evaluation of vascular function can be reliably assessed by these techniques, provided that testing conditions are adequate. Briefly, the different techniques described should be performed by a trained ultrasound technician, with the child being recumbent for $10 \mathrm{~min}$ in the supine position and room temperature kept around $22^{\circ} \mathrm{C}$. As the cooperation of the child is needed for 15-30 min, children younger than 6 y cannot be tested. Standard echo machines can be used with a $7-10 \mathrm{MHz}$ probe. Off line analysis of the images is performed with dedicated software.

\section{ENDOTHELIAL FUNCTION MEASUREMENT}

The measurement of endothelium-dependent (flow mediated) and -independent (nitroglycerine) vascular responses of the brachial artery by high-resolution imaging are performed in subjects laying supine in controlled and consistent testing conditions. Briefly, after baseline brachial artery diameter and blood flow have been recorded, a pneumatic cuff is inflated to suprasystolic pressure on the forearm for 3-5 min. Cuff deflation results in reactive hyperemia, causing increased flow through the brachial artery and stimulating endotheliumdependent, flow-mediated dilation. Arterial diameter measurements are then repeated after a 10-min rest, and 3 and $4 \mathrm{~min}$ after a single sublingual spray of nitroglycerin, which produces an endothelium-independent dilation. Differences between baseline and maximal response to hyperemia and to nitroglycerine are then calculated.

\section{ASSESSMENT OF ARTERIAL STIFFNESS}

Three groups of noninvasive methods are used: 1) measuring pulse wave velocity (PWV), 2) relating change in diameter (or area) of an artery to distending pressure, and 3) assessing arterial pressure waveforms.

Pulse wave velocity. The velocity of the arterial wave propagation is an index of vascular stiffness and has emerged as an important predictor of cardiovascular events. PWV is defined by the Moens-Korteweg equation, $\mathrm{PWV}=\sqrt{ }(\mathrm{Eh} / 2 \rho \mathrm{R})$, where $\mathrm{E}$ is Young's modulus of the arterial wall, $\mathrm{h}$ is wall thickness, $\mathrm{R}$ is arterial radius at the end of diastole, and $\rho$ is blood density. The arterial pulse wave is recorded at proximal artery, such as the common carotid artery, as well as at more distal artery, such as the femoral. The superficial location of these vessels means that their pulse pressure waveforms are readily measured noninvasively, and, between these two sites, the pulse wave has to travel through most of the aorta. The time delay between the arrival of a predefined part of the pulse wave at these two points is obtained by gating to the peak of the $\mathrm{R}$-wave of the ECG. The distance traveled by the pulse wave is measured over the body surface and PWV is then calculated as distance/time $(\mathrm{m} / \mathrm{s})$. Arterial pulse waves can be detected by using pressure-sensitive transducers, Doppler ultrasound, or application tonometry. As increases in distending pressure increase PWV, it is crucial to take into account the level of blood pressure in studies that use PWV as a marker of cardiovascular risk.

Relating change in vessel diameter to distending pressure. The change in arterial diameter during the cardiac cycle evaluated by high-resolution ultrasound can be related to the distending pressure, providing a series of direct measures of stiffness $(8,9)$. Calculation of parameters, such as compliance and distensibility, requires that the incremental pressure of the artery in question be known, for example, the carotid pulse pressure. Applanation tonometry can be used to assess carotid pulse pressure. Arterial compliance and distensibility evaluate the function of the studied artery as a hollow structure. The cross-sectional area of the arterial wall and, therefore, its thickness, is accounted for the calculation of the Young's elastic modulus Einc. Einc is therefore a parameter independent of the arterial geometry and may be considered a measure of the intrinsic stiffness of the arterial wall material. An alternative approach to characterize elastic properties of the arterial wall independently of distending pressure is the calculation of the stiffness index $\beta$ defined as the ratio of logarithm (systolic/diastolic pressures) to (relative change in diameter).

Analysis of the arterial pulse wave form. Pulse wave form can be acquired noninvasively using a high-fidelity, transcutaneous, single-unit, hand-held applanation tonometer with an external coplanar micromanometer tip (Millar Instruments, Houston, TX). Under optimal conditions for applanation (i.e. when the flat tonometer end with coplanar sensor flattens the wall of an artery at the operational part of the sensor), pressures waves measured noninvasively are virtually identical to those recorded with a high-fidelity intra-arterial transducer, and provides a noninvasive means for recording high-fidelity arterial pressure (10). This technique can be easily applied in children. The waveforms and transfer function are used to derive central aortic pressure indices. From this ascending aortic wave form, the aortic pulse pressure $\left(\mathrm{PP}_{\mathrm{Ao}}\right)$, mean pressure, and the augmentation index (AI) are determined. The $\mathrm{AI}$ is defined as the increment in pressure after the first systolic shoulder to the peak of the aortic pressure expressed as a percentage of aortic pulse pressure (11). The first peak (P1) is caused by the left ventricular ejection, whereas the second peak $(\mathrm{P} 2)$ is a result of wave reflection $\mathrm{AI}=(\mathrm{P} 2-\mathrm{P} 1) / \mathrm{PP}_{\mathrm{Ao}}(12)$. $\mathrm{PP}$ depends on arterial stiffness, stroke volume, and timing of reflected pressure waves (13). Elevated AI, PWV, and PP are also associated with left ventricular hypertrophy and increased intima-media thickness of conduit arteries (14-16). 
There are now a number of studies demonstrating the independent prognostic value of either endothelial dysfunction or increased arterial stiffness. These two alterations of arterial function properties usually coexist in patients at risk of cardiovascular events. Some studies in children have directly related increased stiffness with impaired endothelial function, for example, in low birth weight, familial hypercholesterolemia, and severe obesity. This suggests that cardiovascular risk factors may exert their detrimental effects on arterial stiffness through endothelial dysfunction. This hypothesis is corroborated by the observation of endothelial dysfunction without increase in intima-media thickness in most of pediatric studies in young children.

\section{ARTERIAL DYSFUNCTION IN PEDIATRIC CONDITIONS}

The assessment of vascular function may be of interest in different pediatric conditions. Children may have a cardiovascular risk factor identical to those observed in the adult population, such as hypercholesterolemia, diabetes, obesity, smoking, or hypertension. But, the pediatric patients may also be exposed to an atherogenic stimulus that will last longer than in the adult population because it is either related to a congenital anomaly such as coarctation of the aorta, or to side effects of a chronic treatment such as in end-stage renal disease, parenteral nutrition, or antiretroviral therapy in HIV infection. In these two categories of children, early detection of alteration of the vascular properties may help to adapt the long-term management of the disease to delay or improve vascular injury.

\section{EFFECTS OF GROWTH OF ARTERIAL PROPERTIES}

Pressure waves in children are quite unlike those seen in adolescents and paradoxically are similar to those recorded in older adults, as shown by the decrease of the amplification of the pressure wave between the aorta and brachial artery. In neonates, the aortic and radial pressure waves resemble those recorded in elderly. These apparently paradoxical results can be explained on the basis of difference in body length and of the timing of wave reflection. Children appear similar to older subjects because reflected waves return earlier to central arteries and have their most pronounced effect on the systolic rather than the diastolic part of the pressure pulse.

Invasive study of arterial compliance and stiffness of the proximal aorta have been investigated in subjects from 6 mo to 20 y (17). Compliance increases with growth and correlates with increase in arterial size. Arterial distensibility decreases with age and is documented by an increase in wall stiffness of the proximal aorta with age. This suggests that the increase in arterial size that accompanies increased body size counterbalances in young subjects the effects of age on intrinsic properties of arterial wall.

Recently, evidence has accumulated that cardiovascular disease is not only predicted by key risk factors but also by antenatal events $(18,19)$. Low birth weight has been related to mortality from coronary disease and to the development of hypertension and diabetes. Endothelial dysfunction in children, adolescents, and young adults has been correlated with birth weight (20). It appears within the first decade of life before the acquisition of any risk factor burden. Aging and prenatal influences could act synergistically on vascular function. The association between birth weight and endothelial dysfunction continues into the third decade of life and this suggests that low birth weight may adversely influence vascular function and the pathogenesis of early atherosclerosis in subjects with low risk profile to a similar degree of more widely recognized acquired risk influences, such as smoking $(21,22)$. As endothelial function can be modified by appropriate interventions, these observations emphasize the need for early identification of at-risk pediatric patients, because reduction of classic risk factors introduced in adult life can only have a limited impact on cardiovascular outcome in this population who had an intrauterine growth retardation.

Cuomo et al. (23) showed that arterial abnormalities in individuals with a familial predisposition to coronary artery disease occur early and can be easily detected in children. Together with prenatal history, these findings support the notion that preventive efforts aimed at reducing the burden of atherosclerosis in the population should begin early in life.

\section{CLASSIC RISK FACTORS AND VASCULAR DYSFUNCTION}

Endothelial dysfunction and increased arterial stiffness of the carotid are present in children with heterozygous familial hypercholesterolemia (24-28). This vascular dysfunction appears in children as young as 6 or 7 y of age. Intima-media thickness is also increased in these children and areas of plaque, defined as distinct protrusion into the vessel wall, are present in $10 \%$ of the familial hypercholesterolemic children but only in one of the controls (29). The relationship between vascular dysfunction/remodeling and LDL cholesterol levels is still unclear, as is an amplifying role of family history of early cardiovascular events. Because raised LDL cholesterol levels can be lowered effectively, early statin therapy has been used with encouraging results to improve endothelial function in children (30). These findings emphasize the relevance for early statin therapy in children with familial hypercholesterolemia to reverse the atherosclerotic process.

Endothelial dysfunction has been demonstrated in children with other conditions such as combined hyperlipidemia and type 1 diabetes mellitus. In this latter condition, increased carotid artery intima-medial thickness was found to be correlated with the duration of the diabetes (31-35). Pena et al. (36) showed that folic acid improves endothelial function in children and adolescents with type 1 diabetes mellitus.

Obesity has become a major public issue. Recent studies provided evidence that severe childhood obesity is associated with early endothelial dysfunction and increased stiffness of elastic arteries. Alteration of mechanical properties of the abdominal aorta has been described in obese children (37). A strongly positive correlation between flow-mediated dilation and plasma apolipoprotein A-1 concentration was found independently of insulin resistance. The reversibility of such early arterial damage in children with an intervention program of 
diet alone or diet with exercise training seems to be effective strategies to improve obesity-related vascular abnormalities $(38,39)$

These various studies in pediatric populations indicate that endothelial dysfunction and carotid thickening found in conditions predisposing to atherosclerosis may be present at a young age (31-39). The fact that specific pediatric atherogenic conditions and classic risk factors are common correlates of both flow-mediated vasodilatation and carotid thickening suggest that endothelial dysfunction is a facet of arterial wall remodeling. A negative correlation between brachial artery flow-mediated vasodilatation and carotid intima-medial thick-

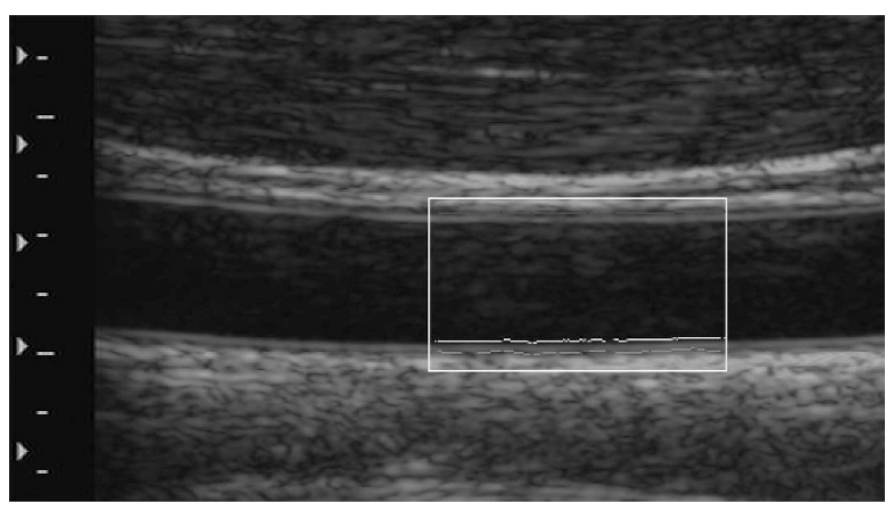

Figure 1. Parallel longitudinal view of the common carotid artery showing near and far wall. The intima-lumen (I-L) interface (red line) of the anterior wall artery and both the lumen-intima (green line) and media-adventitia (red line) interfaces on the distal portion are shown. The proximal and distal walls are detected automatically by analyzing the mean gray-level profile of the frame ness has been shown in children and young adults (40). These alterations of vascular function in at-risk children could be useful markers of preclinical vascular disease and may help evaluate the risk modification by therapeutic interventions. Additionally, these methods could be a useful tool for risk stratification in children at risk, thereby permitting identification of children who would benefit most from intensified therapy.

\section{"NONCLASSIC" CARDIOVASCULAR RISK FACTORS}

End stage renal disease (ESRD) in adults is associated with severe vascular dysfunction and remodeling. Only a few studies have documented the consequence of renal failure on arterial function in children. The main finding of the impact of end-stage renal insufficiency in children undergoing hemodialysis on arterial function has shown that mechanical properties of the common carotid artery was altered, characterized by a decrease of compliance and distensibility with increased incremental elastic modulus (41). In this latter study, the intima media thickness and the wall stress were significantly higher in the ESRD group. Common carotid cross-sectional compliance and distensibility were significantly lower in the ESRD group. The augmentation index was significantly increased in ESRD children because of an early wave reflection on the carotid pressure curve. Additionally, ESRD patients had an increased carotid pulse pressure when compared with controls $(40 \pm 9$ $\mathrm{mm} \mathrm{Hg}$ versus $34 \pm 5 \mathrm{~mm} \mathrm{Hg}, p<0.05)$ due to increased pulse wave velocity. The local pulse pressure at the carotid site correlated positively with the intima media thickness $(r=0.63$, $p<0.01)$. The flow-mediated dilatation and the glyceryl
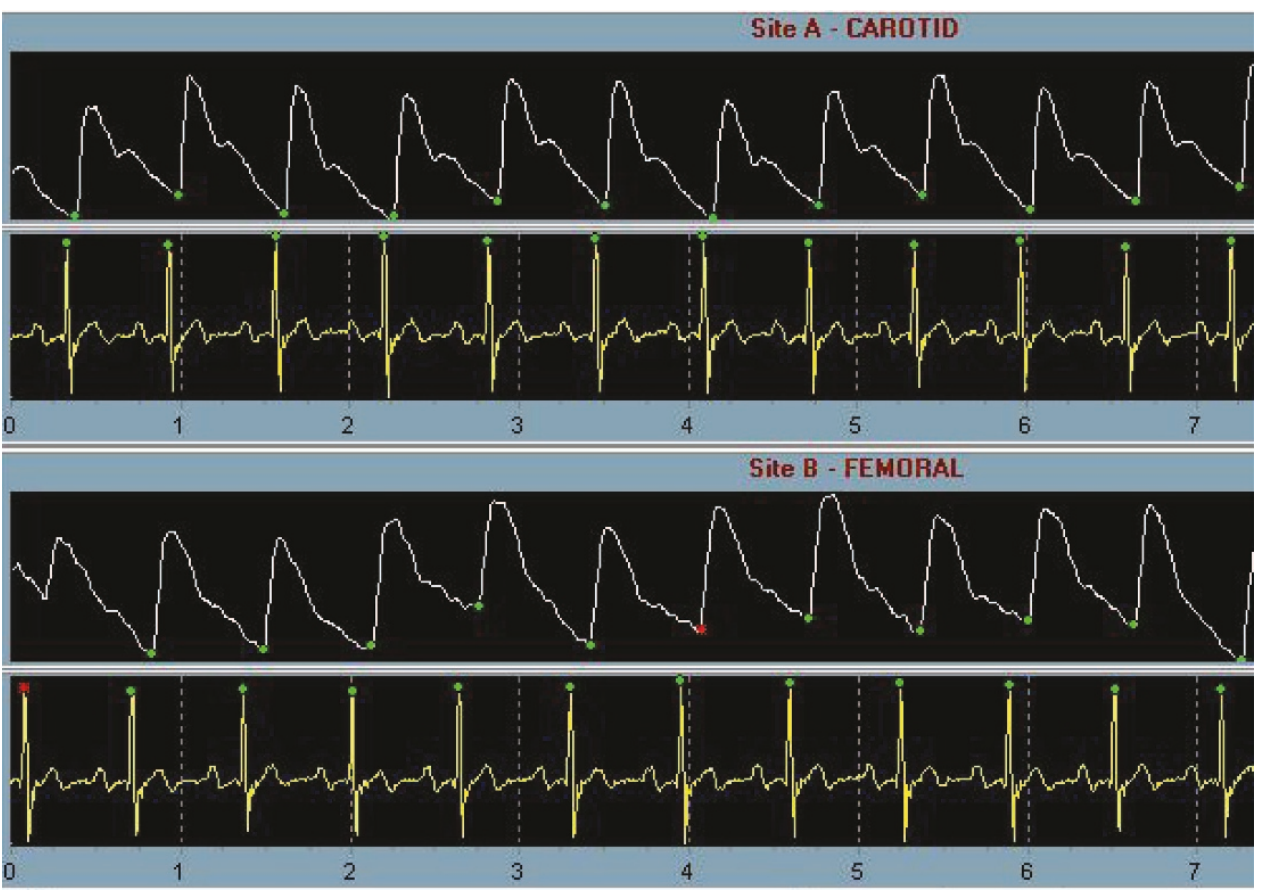

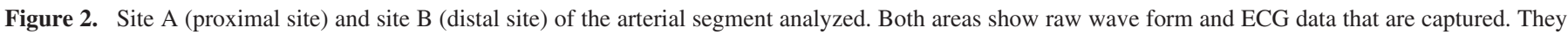

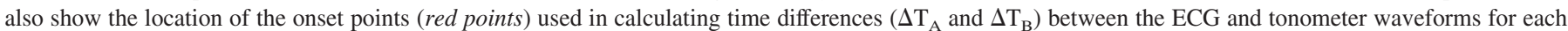

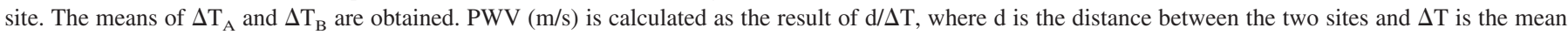
difference in time $\left(\Delta \mathrm{T}_{\mathrm{A}}-\Delta \mathrm{T}_{\mathrm{B}}\right)$. 
(A)

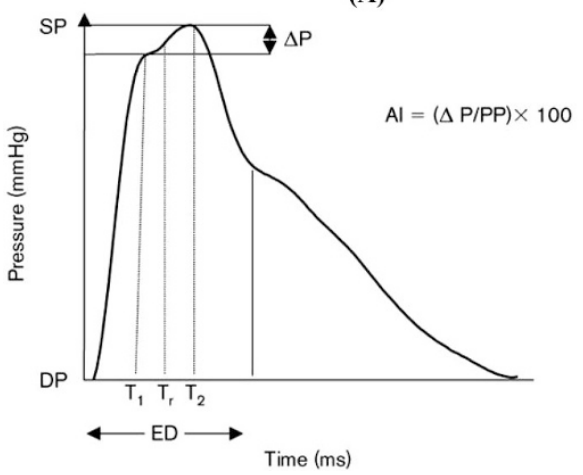

(B)

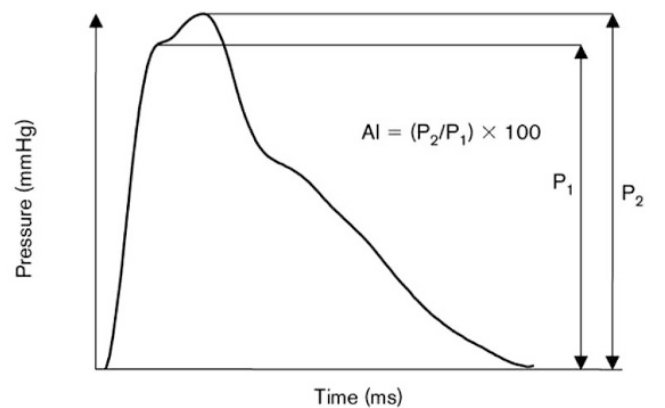

Time (ms)

Figure 3. The PWA system derives from the peripheral pressure wave form recorded at the radial artery the central aortic pressure wave form and a range of central artery indices: Augmentation index $(\mathrm{AI})=\Delta \mathrm{P} / \mathrm{PP} \times 100$ or $(\mathrm{P} 2 / \mathrm{P} 1) \times 100$, where $\Delta \mathrm{P}$ is the difference between $\mathrm{P} 2$ and $\mathrm{P} 1$, respectively, the pressures at times T2 and T1, and PP, the pulse pressure [systolic blood pressure (SP) - diastolic blood pressure (DP)]. Tr defines time to return of the reflection wave of the aortic wave form and ED the ejection duration.

trinitrate-mediated dilatation were significantly lower in ESRD group (by $37.5 \%$ and $22 \%$, respectively, $p<0.01$ ). Transplanted children also show endothelial dysfunction and increased arterial stiffness (42). In these patients, the flowmediated dilation was less than in controls and was associated with hypertension.

In children, total or complementary parenteral nutrition is a well-established intervention in acute or chronic illnesses that limit oral feeding, impair digestive function, and threaten nutritional status. The repercussions of parenteral nutrition on structure and function of arteries in children has not been widely evaluated but our group recently showed an increase in the arterial stiffness associated with an impairment of the endothelium function in this condition (43). The exact mechanism through which parenteral nutrition might accelerate the formation of atheromatous lesion is unclear.

Since highly active antiretroviral therapy was introduced, life expectancy of human immunodeficiency virus (HIV)infected children has increased. The adverse effects of antiretroviral therapy, including dyslipidemias, lipodystrophy, insulin resistance, and premature atherosclerosis, are cause of concern for there use in chronic management of HIV infection $(44,45)$. This is of particular importance in children because HIV infection has become a chronic disease in this population, with a potential for two decades longer term survival than adults. The relative contribution of antiretroviral therapy, chronic inflammation due to the ongoing viral infection, classic cardiovascular risk factors, and their interaction is very difficult to identify in adults. The pediatric population may help to disentangle the viral infection from antiretroviral therapy influences on vascular injury during HIV infection in the absence of classic cardiovascular risk factors. We recently showed that HIV-infected children had a vascular dysfunction that may be an early step in the development of atherosclerosis (46). Our findings were surprising as we did not find any difference between children receiving antiretroviral therapy and untreated patients.

Persistent vascular dysfunction has been suspected to be an important contributor to abnormal blood pressure regulation and, thus, late cardiovascular morbidity and mortality after successful coarctation repair (47-49). Modification of the up- per limb vascular phenotype has been demonstrated in patients operated upon in early infancy, suggesting that endothelial and smooth muscle functional abnormalities could persist despite early repair. Vascular stiffness may be linked to hypertension through various potential mechanisms (49), but it remains unclear whether these factors (age at repair, geometry of the aortic arch) are causative (50). Coarctation of the aorta is a pediatric condition in which intervention either on vascular dysfunction itself or on causative mechanisms such as aortic arch geometry could help to delay the onset of resting hypertension and consequently to reduce late cardiovascular events. (Figs. 1-3)

\section{CONCLUSION}

Ultrasound evaluation of vascular function in patients at risk for atherosclerosis is applied in clinical practice. In pediatric patients, the main limitation of these techniques is their observational character. But there is no reason why assessment of vascular dysfunction in children could be of less benefit than in adults. The significance of endothelial dysfunction and intimamedial thickening and their long-term consequences remain unknown. Endothelial dysfunction and alteration of the mechanical properties of the arterial wall are observed early in life in children harboring classic cardiovascular risk factors or conditions known to confer a risk of premature atherosclerosis in adults. Longitudinal studies are needed to evaluate the impact of interventions on vascular function. These methods already provide a valuable adjunct for the stratification of the prognosis as well as for the guidance of therapeutic interventions in children with increased cardiovascular risk.

\section{REFERENCES}

1. Berenson GS, Srinivasan SR, Bao W, Newman W, Tracy RE, Wattigney WA 1998 Association between multiple cardiovascular risk factors and atherosclerosis in children and young adults. The Bogalusa Heart Study. N Engl J Med 338:1650-1656

2. Newman WP 3rd, Wattigney W, Berenson GS 1991 Autopsy studies in United States children and adolescents. Relationship of risk factors to atherosclerotic lesions. Ann N Y Acad Sci 623:16-25

3. Celermajer DS, Sorensen KE, Gooch VM, Spiegelhalter DJ, Miller OI, Sullivan ID, Lloyd JK, Deanfield JE 1992 Non-invasive detection of endothelial dysfunction in children and adults at risk of atherosclerosis. Lancet 340:1111-1115 
4. de Groot E, Hovingh K, Wiegman A, Duriez P, Smit AJ, Fruchart JC, Kastelein JJ 2004 Measurement of arterial wall thickness as a surrogate marker for atherosclerosis. Circulation 109:III-3-III-38

5. Davies JI, Struthers AD 2003 Pulse wave analysis and pulse wave velocity: a critical review of their strengths and weaknesses. J Hypertens 21:463-472

6. Chen CH, Nevo E, Fetics B, Pak PH, Yin FC, Maughan WL, Kass DA 1997 Estimation of central aortic pressure waveform by mathematical transformation of radial tonometry pressure. Validation of generalized transfer function. Circulation 95:1827-1836

7. Corretti MC, Anderson TJ, Benjamin EJ, Celermajer D, Charbonneau F, Creager MA, Deanfield J, Drexler H, Gerhard-Herman M, Herrington D, Vallance P, Vita J, Voge R, International Brachial Artery Reactivity Task Force 2002 Guidelines for the ultrasound assessment of endothelial-dependent flow-mediated vasodilation of the brachial artery: a report of the International Brachial Artery Reactivity Task Force. J Am Coll Cardiol 39:257-265

8. Nichols WW, O'Rourke MF 1998 McDonald's Blood Flow in Arteries, 4th Ed. Arnold, London

9. Graf S, Gariepy J, Massonneau M, Armentano RL, Mansour S, Barra JG, Simon A, Levenson J 1999 Experimental and clinical validation of arterial diameter waveform and intima media thickness obtained from B-mode ultrasound image processing. Ultrasound Med Biol 25:1353-1363

10. Davies JI, Band MM, Pringle S, Ogston S, Struthers AD 2003 Peripheral blood pressure measurement is as good as applanation tonometry at predicting ascending aortic blood pressure. J Hypertens 21:571-576

11. Chen CH, Nevo E, Fetics B, Pak PH, Yin FC, Maughan WL, Kass DA 1997 Estimation of central aortic pressure waveform by mathematical transformation of radial tonometry pressure. Validation of generalized transfer function. Circulation 95:1827-1836

12. van Bortel LM, Hoeks AP, Kool MJ, Struijker-Boudier HA 1992 Introduction to large artery properties as a target for risk reduction by antihypertensive therapy. J Hypertens 10:S123-S126

13. Authors, title

14. Millar JA, Lever AF 2000 Implications of pulse pressure as a predictor of cardiac risk in patients with hypertension. Hypertension 36:907-911

15. Saba PS, Roman MJ, Pini R, Spitzer M, Ganau A, Devereux RB 1993 Relation of arterial pressure waveform to left ventricular and carotid anatomy in normotensive subjects. J Am Coll Cardiol 22:1873-1880

16. Yasmin, Brown MJ 1999 Similarities and differences between augmentation index and pulse wave velocity in the assessment of arterial stiffness. QJM 92:595-600

17. Senzaki H, Akagi M, Hishi T, Ishizawa A, Yanagisawa M, Masutani S, Kobayashi T, Awa S 2002 Age-associated changes in arterial elastic properties in children. Eur J Pediatr 161:547-551

18. Singhal A, Kattenhorn M, Cole TJ, Deanfield J, Lucas A 2001 Preterm birth, vascular function, and risk factors for atherosclerosis. Lancet 358:1159-60

19. Barker DJ 1993 Fetal origins of coronary heart disease. Br Heart J 69:195-96

20. Cheung YF, Wong KY, Lam BC, Tsoi NS 2004 Relation of arterial stiffness with gestational age and birth weight. Arch Dis Child 89:217-221

21. Oren A, Vos LE, Bos JW, Safar ME, Uiterwaal CS, Gorissen WH, Grobbee DE, Bots ML 2003 Gestational age and birth weight in relation to aortic stiffness in healthy young adults: two separate mechanisms? Am J Hypertens 16:76-79

22. Leeson CP, Kattenhorn M, Morley R, Lucas A, Deanfield JE 2001 Impact of low birth weight and cardiovascular risk factors on endothelial function in early adult life. Circulation 103:1264-1268

23. Cuomo S, Guarini P, Gaeta G, De Michele M, Boeri F, Dorn J, Bond M, Trevisan M 2002 Increased intima-media thickness in children-adolescents, and young adults with a parental history of premature myocardial infarction. Eur Heart J 23:1345-1350

24. Iannuzzi A, Rubba P, Pauciullo P, Celentano E, Capano G, Sartorio R, Mercuri M, Bond MG 1999 Stiffness of the aortic wall in hypercholesterolemic children. Metabolism 48:55-59

25. Aggoun Y, Bonnet D, Sidi D, Girardet JP, Brucker E, Polak M, Safar ME, Levy BI 2000 Arterial mechanical changes in children with familial hypercholesterolemia. Arterioscler Thromb Vasc Biol 20:2070-2075

26. Wiegman A, de Groot E, Hutten BA, Rodenburg J, Gort J, Bakker HD, Sijbrands EJ, Kastelein JJ 2004 Arterial intima-media thickness in children heterozygous for familial hypercholesterolemia. Lancet 363:369-370

27. Sorensen KE, Celermajer DS, Georgapoulos D, Hatcher G, Betteridge DJ, Deanfield JE 1994 Impairment of endothelium-dependent dilation is an early event in children with familial hypercholesterolemia and is related to the lipoprotein (a) level. J Clin Invest 93:50-55
28. Virkola K, Pesonen E, Akerblom HK, Siimes MA 1997 Cholesterol and carotid artery wall in children and adolescents with familial hypercholesterolaemia: a controlled study by ultrasound. Acta Paediatr 86:1203-1207

29. Pauciullo P, Iannuzzi A, Sartorio R, Irace C, Covetti G, Di Costanzo A, Rubba P 1994 Increased intima-media thickness of the common carotid artery in hypercholesterolemic children. Arterioscler Thromb 14:1075-1079

30. de Jongh S, Lilien MR, op't Roodt J, Stroes ES, Bakker HD, Kastelein JJ 2002 Early statin therapy restores endothelial function in children with familial hypercholesterolemia. J Am Coll Cardiol 40:2117-2121

31. Järvisalo MJ, Raitakari M, Toikka JO, Putto-Laurila A, Rontu R, Laine S, Lehtimäki T, Rönnemaa T, Viikari J, Raitakari OT 2004 Endothelial dysfunction and increased arterial intima-media thickness in children with type 1 diabetes. Circulation 109:1750-1755

32. Pomilio M, Mohn A, Verrotti A, Chiarelli F 2002 Endothelial dysfunction in children with type 1 diabetes mellitus. J Pediatr Endocrinol Metab 15:343-361

33. Romano M, Pomilio M, Vigneri S, Falco A, Chiesa PL, Chiarelli F, Davi G 2001 Endothelial perturbation in children and adolescents with type 1 diabetes: association with markers of the inflammatory reaction. Diabetes Care 24:1674-1678

34. Singh TP, Groehn H, Kazmers A 2003 Vascular function and carotid intima-medial thickness in children with insulin-dependent diabetes mellitus. J Am Coll Cardiol 41:661-663

35. Jarvisalo MJ, Jartti L, Nanto-Salonen K, Irjala K, Ronnemaa T, Hartiala JJ, Celermajer DS, Raitakari OT 2001 Increased aortic intima-media thickness: a marker of preclinical atherosclerosis in high-risk children. Circulation 104:2943-2947

36. Pena AS, Wiltshire E, Gent R, Hirte C, Couper J 2004 Folic acid improves endothelia function in children and adolescents with type 1 diabetes. J Pediatr 144:500-504

37. Tounian P, Aggoun Y, Dubern B, Varille V, Guy-Grand B, Sidi D, Girardet JP, Bonnet D 2001 Presence of increased stiffness of the common carotid artery and endothelial dysfunction in severely obese children: a prospective study. Lancet 358:1400-1404

38. Watts K, Beye P, Siafarikas A, O'Driscoll G, Jones TW, Davis EA, Green DJ 2004 Effects of exercise training on vascular function in obese children. J Pediatr 144:620 625

39. Woo KS, Chook P, Yu CW, Sung RY, Qiao M, Leung SS, Lam CW, Metreweli C, Celermajer DS 2004 Effects of diet and exercise on obesity-related vascular dysfunction in children. Circulation 109:1981-1986

40. Gaeta G, De Michele M, Cuomo S, Guarini P, Foglia MC, Bond MG, Trevisan M 2000 Arterial abnormalities in the offspring of patients with premature myocardial infarction. N Engl J Med 343:840-846

41. Aggoun Y, Niaudet P, Laffont A, Sidi D, Kachaner J, Bonnet D 2000 Cardiovascular impact of end-stage renal insufficiency in children undergoing hemodialysis. Arch Mal Coeur Vaiss 93:1009-1013

42. Lilien MR, Stroes ES, Op't Roodt J, de Jongh S, Schroder CH, Koomans HA 2003 Vascular function in children after renal transplantation. Am J Kidney Dis 41:684691

43. Aggoun Y, Colomb V, Turanlahti M, Corriol O, Goulet O, Sidi D, Ricour C, Bonnet D 2004 Endothelial function and mechanical properties of the common carotid artery in children on parenteral nutrition. Pediatr Res 55:789-793

44. Carr A, Cooper DA 2000 Adverse effects of antiretroviral therapy. Lancet 356:1423 1430

45. Depairon M, Chessex S, Sudre P, Rodondi N, Doser N, Chave JP, Riesen W, Nicod P, Darioli R, Telenti A, Mooser V, Swiss HIV Cohort Study 2001 Premature atherosclerosis in HIV-infected individuals-focus on protease inhibitor therapy. AIDS 15:329-334

46. Bonnet D, Aggoun Y, Szezepanski I, Bellal N, Blanche S 2004 Arterial stiffness and endothelial dysfunction in HIV-infected children. AIDS 18:1037-1041

47. Guenthard J, Wyler F 1995 Exercise-induced hypertension in the arms due to impaired arterial reactivity after successful coarctation resection. Am J Cardio 75:814-817

48. de Divitiis M, Pilla C, Kattenhorn M, Donald A, Zadinello M, Wallace S, Redington A, Deanfield J 2003 Ambulatory blood pressure, left ventricular mass, and conduit artery function late after successful repair of coarctation of the aorta. J Am Coll Cardiol 41:2259-2265

49. Aggoun Y, Sidi D, Bonnet D 2001 Arterial dysfunction after treatment of coarctation of the aorta. Arch Mal Coeur Vaiss 94:785-789

50. Ou P, Bonnet D, Auriacombe L, Pedroni E, Balleux F, Sidi D, Mousseaux E 2004 Late systemic hypertension and aortic arch geometry after successful repair of coarctation of the aorta. Eur Heart J 25:1853-1859 